Mirjana Arsenijević

Arheološki institut Beograd

Saša Redžić

Arheološki institut Beograd

Milica Tapavički-Ilić

Arheološki institut Beograd

904:731.1.032(37)'04

904:726.821"652"(497.11)

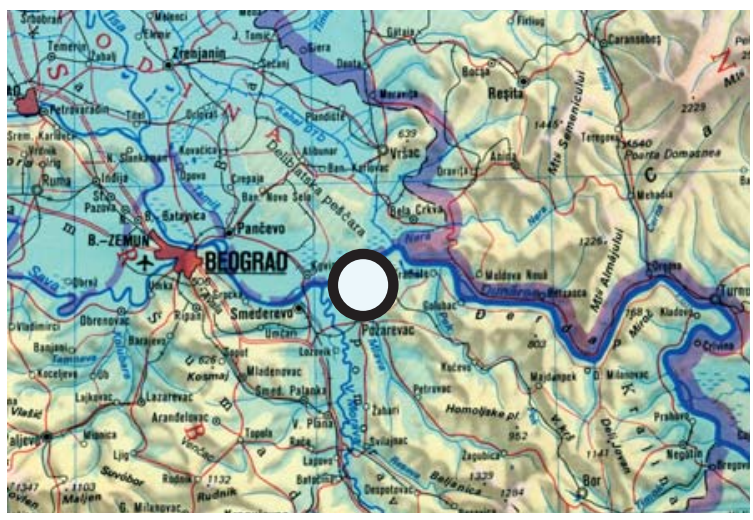

Viminacium, Stari Kostolac, Srbija

LAT 44 44'09" / LONG $21^{\circ} 12^{\prime} 42^{\prime \prime}$

\title{
DVA NOVA TIPA REVERSNIH PREDSTAVA KOVNICE NIKEJE SA NEKROPOLE VIŠE GROBALJA
}

\begin{abstract}
ABSTRAKT
Sa viminacijumske nekropole Više Grobalja potiču dva nova tipa reversnih predstava kovnice Nikeje iz Bitinije. U pitanju su tipovi sa predstavom standarda i legionarskih kaprikorna, kovani za Aleksandra Severa i Trankvilinu.
\end{abstract}

KLJUČNE REČI: KLJUČNE REČI: REVERSNI TIPOVI, VOJNE INSIGNIJE, KOVNICA NiKEJA, ViMINACIJUM.

Proučavanje nalaza sa viminacijumske nekropole pruža mogućnosti za izuzetna i nova otkrića, između ostalog i zato što nam je uvek na raspolaganju veliki uzorak. Preliminarni podaci analize novca sa nekropole Više Grobalja ${ }^{1}$ ukazuju na veći broj sasvim novih tipova, naročito među primercima provincijskog, ali takođe i carskog kovanja. Konačno publikovanje ovih numizmatičkih nalaza predstavljaće veliki doprinos proučavanju rimskog kovanja i još jednom ukazati na veliki značaj koji je imao Viminacijum, kao važna administrativna, ekonomska i vojna metropola u ovom delu Carstva. Pogotovo što ćemo dobiti daleko potpuniju sliku o monetarnoj cirkulaciji, naročito iz istočnih provincija. U ovom smislu, važno mesto zauzima novac kovnice Nikeje iz Bitinije,

1. U toku je izrada kataloga novca pronađenog na ovoj viminacijumskoj nekropoli. koji je u velikom broju zastupljen na nekropoli Više Grobalja. Nešto su ređi primerci nikejskog kovanja pre Aleksandra Severa, dok kovanje za ovog cara, čini najveći deo pronađenog novca, da bi primerci Gordijana III ponovo bili daleko ređi, a posle njega sasvim sporadični. Ove činjenice još jednom ukazuju na veliko prisustvo novca Nikeje u Podunavlju do otvaranja kovnice provincijskog novca u Viminacijumu 239. godine. ${ }^{2}$

Repertoar reversnih predstava nikejskog kovanja proširen je novim nalazima sa Viminacijuma. U pitanju su dva nova tipa sa vojnim insignijama i legionarskim kaprikornima. ${ }^{3}$ Metodologija razvrstavanja reversnih tipova, koju je upotrebio N. Crnobrnja, prilikom publikovanja

2. Црнобрња 1981: 5, n. 3-7.

3. C - 9275 (G1-1357), C - 767 (pronađen u sloju) i C -4280 (G-624). 

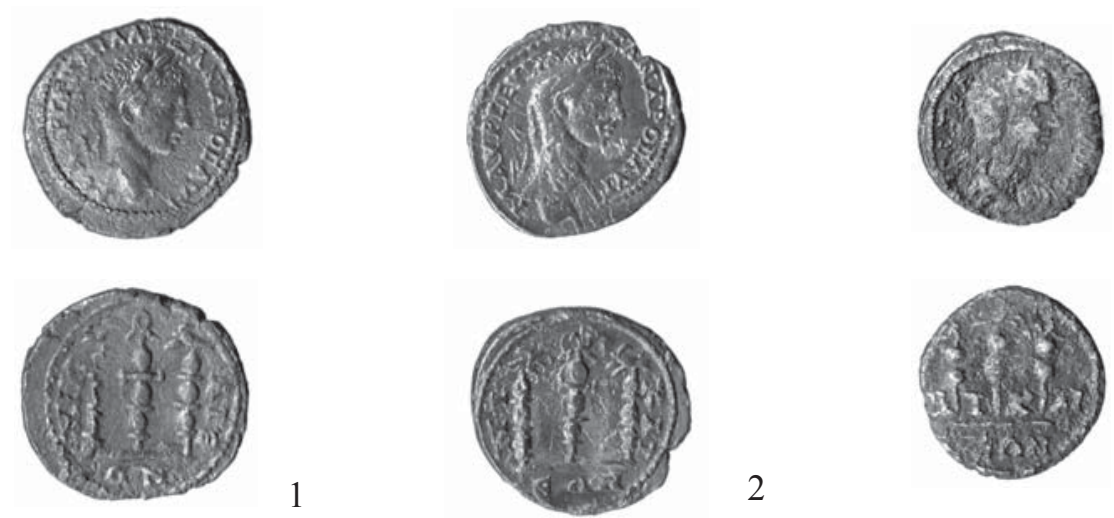

2 3

novca grada Nikeje iz zbirke Muzeja grada Beograda, predstavlja pravi način za detaljnu analizu razvoja pojedinih predstava. ${ }^{1}$ Iz ovog razloga odlučili smo da koristimo njegovu podelu i dopunimo je novim tipovima. ${ }^{2}$

Viminacijumski primerci Aleksandra Severa sa legionarskim kaprikornima i vojnom insignijom označeni su kao tip 29. Natpis na reversu pripada ređem načinu ispisivanja legendi u nikejskom kovanju u kombinaciji sa vojnim insignijama, zato što ide duž ivice novčića, a ne između insignija kao što je uobičajeno. Predstavljena je jedna vojna insignija između dva legionarska kaprikorna (Sl. 1, 2).

1. C -9275

Av. M AVP CEVH A $\Lambda$-E $\Xi A N \triangle P O C ~ A V \Gamma$

Bista cara $\mathrm{s}$ lovorovim vencem na desno, poprsje pod paludamentumom.

Rv.

NI-KAI (okolo)

$\mathrm{E} \Omega \mathrm{N}(\mathrm{ex})$

težina - 4,35 gr; prečnik - 20,3 mm; osa 1850 .

Kat. BMC Bithynia 99-103; WBR 617; Weiser 030 .

\section{2. $\mathrm{C}-767$}

Av.

M AVP CEVH A $\Lambda$ E $\Xi A N \triangle P O C$ AVГ (AVГ u ligaturi)

1. Црнобрња 1981: 6, Tabela 2.

2. U Tabeli 2 N. Crnobrnja dodao je 12 tipova sa predstavom vojnih insignija i 16 sa legionarskim orlom ili kaprikornima u kombinaciji sa insignijama. Vidi n. 4.
Bista cara s lovorovim vencem na desno, poprsje pod paludamentumom.

Rv.

NIK-AIE (okolo)

$\Omega \mathrm{N}(\mathrm{ex})$

težina - 5,26 gr; prečnik - 20,2 mm; osa 1850.

Kat. BMC Bithynia 99-103; WBR 617; Weiser $030 .{ }^{3}$

Još jedan novi tip pronađen na Viminacijumu, označen je kao 30 i pripada kovanju Gordijana III za Trankvilinu. U ovom slučaju tip legende pripada češćem, ispisanom između insignija. Prikazan je jedan legionarski kaprikorn u sredini, dok se levo i desno nalazi po jedna vojna insignija (Sl. 3).

3. $\mathrm{C}-4280$

Av.

[CAB] TPANKV $\Lambda$ INA

Bista carice na d. obučena, s dijademom na glavi.

Rv.

N-I-K-AI

$\mathrm{E} \Omega \mathrm{N}(\mathrm{ex})$

težina - 2,94 gr; prečnik - 19,5 mm; osa 50 .

BMC Bithynia 130.

Opisani primerci predstavljaju još jednu kariku u boljem razumevanju razvoja reversnih predstava na novcu Nikeje, a viminacijumski nalazi će sasvim sigurno nadalje razvijati ovu tipologiju.

3. Ni jedan od referentnih kataloga ne izdvaja tipove detaljno, već se ograničavaju na sumarne opise (,tri insignije“ ili „legionarski orao između dve insignije“). 


\section{RESUME}

\section{Two New Types of Reverse Images}

of the Nicaia Mint at the Necropolis

Više Grobalja

Preliminary data obtained by coin analysis from the Više Grobalja necropolis point out to a greater number of completely new coin types, especially among the examples of provincial, but also among the imperial mintings. Apart from typological characteristics of the images, data about monetary circulation given by coin finds from Viminacium are of great importance. In this aspect, an important place is taken by coins from the Nicaia mint in Bithynia, which were quite numerous at the necropolis Više Grobalja. Among them, there are two new types of reverse images of the Nicaia mint with military insignia, which belong to the mintings of Alexander Severus and Gordian III (for Tranquilina).

Translated by M. Tapavički-Ilić

\section{BIBLIOGRAFIJA}

\section{BMC Bithynia 1989.}

W. Worth, Catalogue of Greek coins in the British Museum, Pontus, Paphlagonia, Bithynia, London 1889.

Црнобрња 1981

Н. Црнобрња, Новац града Никеје у нумизматичкој збирци Музеја града Београда, Годишњак града Београда XXVIII, 1981: 5-23

\section{WBR 1910}

W. H. Waddington, E. Babelon, Th. Reinach, Recueil general des Monnaies grecques d'Asie Mineure, Paris 1910.

\section{Weiser 1983.}

W. Weiser, Katalog der Bithynischen Münzen der Sammlung des Instituts für Altertumskunde der Universität zu Köln, Papyrologica Coloniensia XI, Opladen 1983. 

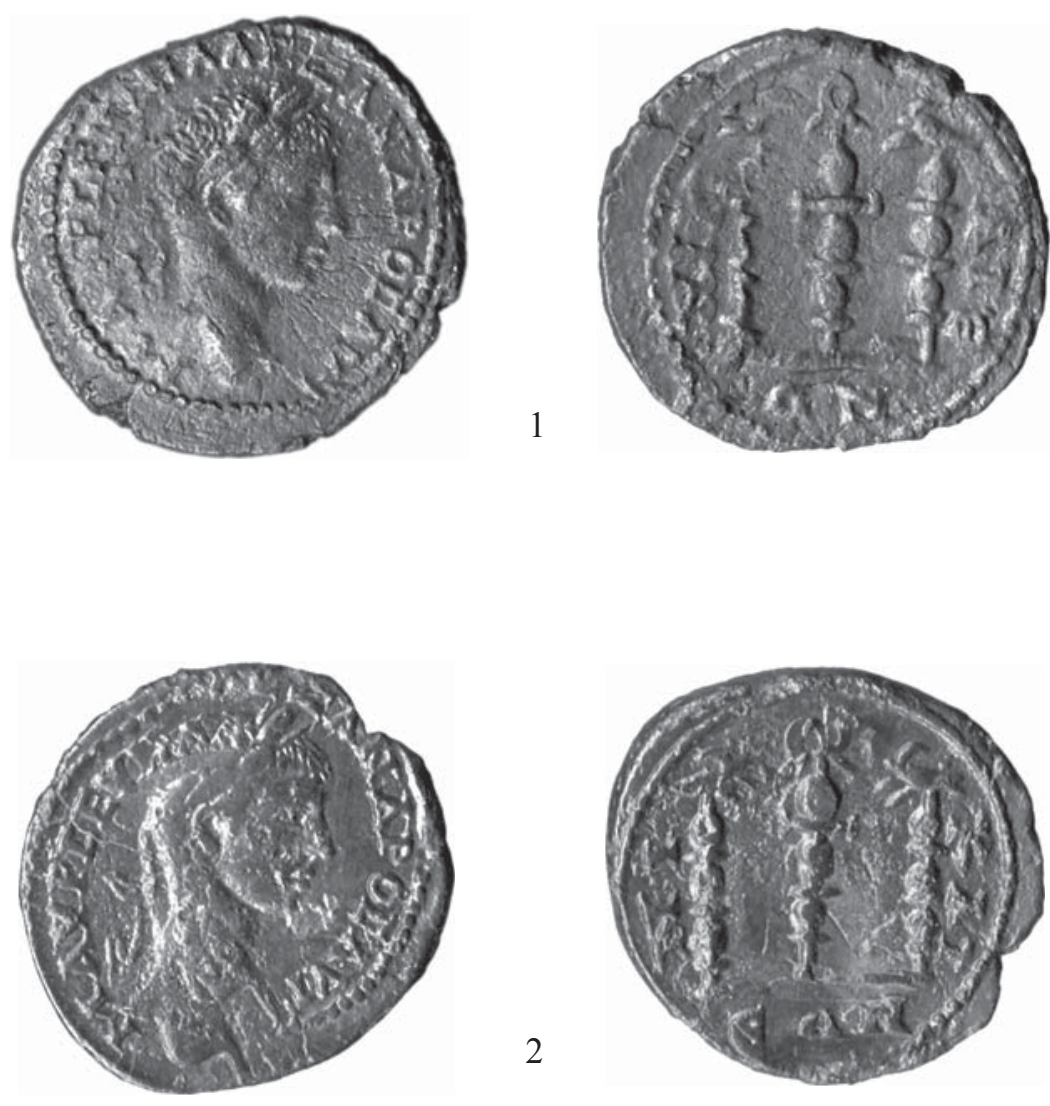

2
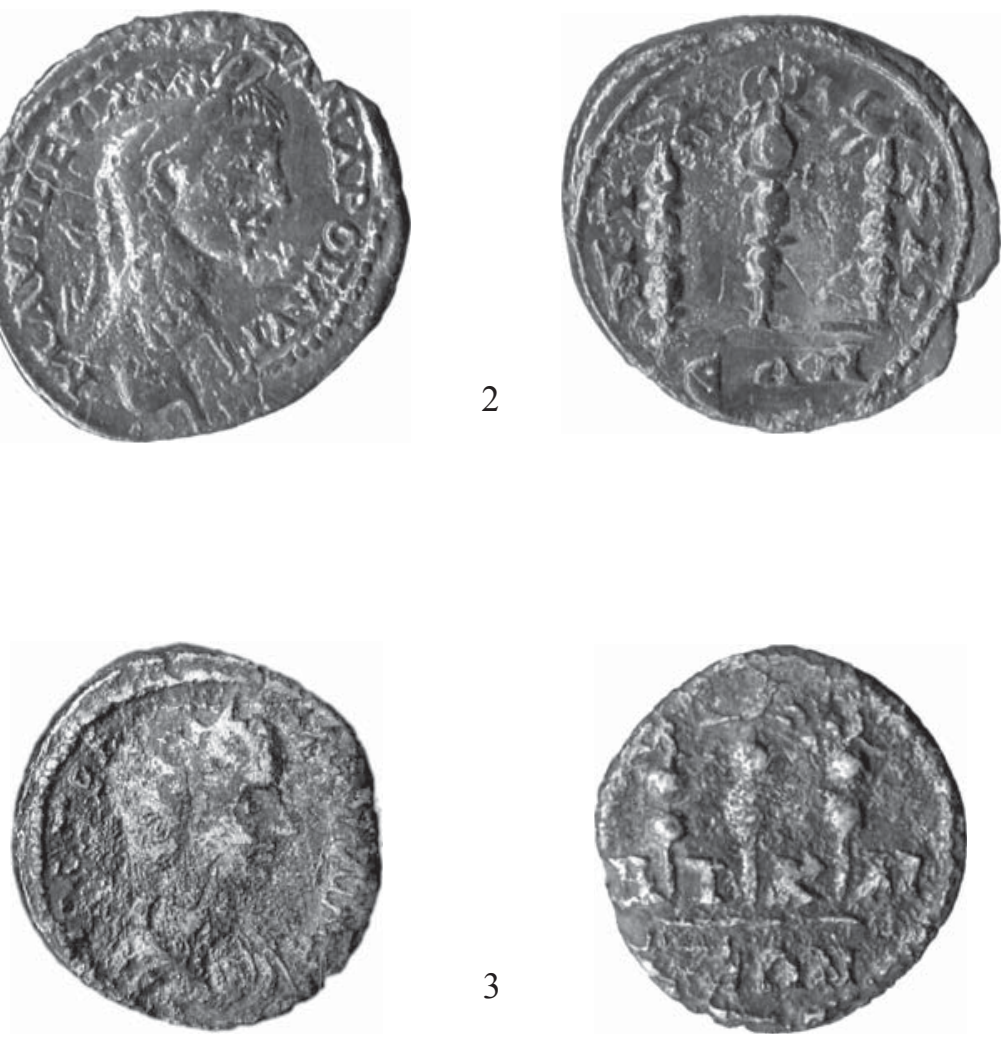

R 2:1 